\title{
Escavar, descobrir e aprender: a arqueologia no processo de ensino-aprendizagem na Educação Básica
}

\author{
Excavar, descubrir y aprender: la arqueología en el proceso de \\ enseñanza-aprendizaje en Educación Básica \\ Discover and learn: archeology in the teaching-learning process in \\ Basic Education
}

\author{
Dr. Washington Kuklinski Pereira ${ }^{1}$
}

\begin{abstract}
Resumo
A disciplina História, na Educação Básica, tem como objetivo a análise das relações humanas desde o período da Pré-História até o período da decadência do Império Romano. O estudo sobre a Pré-História e a Antiguidade dos povos da Mesopotâmia, Egito, Grécia e Roma é distante cronologicamente e geograficamente da realidade dos estudantes brasileiros. Por este motivo, é um grande desafio para os professores de História o desenvolvimento do processo ensino-aprendizagem dessas temáticas. Por estes motivos, o objetivo deste trabalho é investigar e apresentar práticas docentes que, apesar do excesso de abstração para o desenvolvimento dos estudos históricos, que explorem em sala de aula projetos, atividades e práticas pedagógicas que auxiliem o conhecimento histórico sobre a pré-história e a antiguidade, tendo como base as experiências arqueológicas e a multiculturalidade no processo de aprendizagem.
\end{abstract}

Palavras-Chave: Pré-História; Ensino-Aprendizagem; Sala de Aula; Multiculturalidade; Práticas Pedagógicas.

\section{Resumen}

La disciplina Historia, en la Educación Básica, tiene como objetivo el análisis de las relaciones humanas desde el período de la Prehistoria hasta el período de la decadencia del Imperio Romano. El estudio sobre la Prehistoria y la Antigüedad de los pueblos de Mesopotamia, Egipto, Grecia y Roma es distante cronológicamente y geográficamente de la realidad de los estudiantes brasileños. Por este motivo, es un gran desafío para los profesores de historia el desarrollo del proceso enseñanza-aprendizaje de esas temáticas. Por estos motivos, el objetivo de este trabajo es investigar y presentar prácticas docentes que, a pesar del exceso de abstracción para el desarrollo de los estudios históricos, que exploten en el aula proyectos, actividades y prácticas pedagógicas que auxilien el conocimiento histórico sobre la prehistoria y la antigüedad, teniendo como base las experiencias arqueológicas y la multiculturalidad en el proceso de aprendizaje.

Palabras claves: Prehistoria; La enseñanza y el aprendizaje; Clase; Multiculturalismo; Prácticas Pedagógicas.

\section{Abstract}

\footnotetext{
${ }^{1}$ Doutor em História; Secretaria Municipal de Educação do Rio de Janeiro-SME-RJ/Fundação de Estudos do Mar - FEMAR; Rio de Janeiro, Rio de Janeiro, Brasil; washington.kpereira@ rioeduca.net .
} 
The History subject, in the Basic Education, has as its objective the analysis of human relations from the period of Prehistory to the period of the decline of the Roman Empire. The study on the Prehistory and Antiquity of the peoples of Mesopotamia, Egypt, Greece and Rome is distant chronologically and geographically from the reality of Brazilian students. For this reason, it is a great challenge for history teachers to develop the teaching-learning process of these subjects. For these reasons, the objective of this work is to investigate and present teaching practices that, despite the excess of abstraction for the development of historical studies. That exploit in the classroom projects, activities and pedagogical practices that help historical knowledge about prehistory. The antiquity, based on archaeological experiences and multiculturalism in the learning process.

Keywords: Prehistory; Teaching and learning; Class; Multiculturalism; Pedagogical Practices

\title{
1. Introdução
}

Estudantes que iniciam o sexto ano em idade regular, acostumados a terem poucos professores regentes em sala de aula, vivem um importante momento de transição ao ampliar sua diversidade acadêmica. Passam a ter contato com professores especialistas de diversas disciplinas, o que proporciona o aprofundamento dos conteúdos aprendidos na escola. Além disso:

\begin{abstract}
"Na passagem da quarta para a quinta série, acreditamos que os professores deveriam evidenciar práticas que permitissem o desenvolvimento de recursos pessoais dos alunos, até então não acionados, e que as aprendizagens do passado deveriam dialogar com as novas aprendizagens. Esta passagem é vista como um momento de dificuldades, pois os espaços e o ritmo de estudo são diferentes. Esta fase é descrita como uma época de transformações e desafios, especialmente para o aluno." (CAINELLI, 2011) $)^{2}$
\end{abstract}

A experiência do processo ensino-aprendizagem por professores diferentes, com metodologias diferentes proporciona grande amadurecimento acadêmico do estudante. Por isso, o professor não pode desprezar a faixa etária do aluno e a consequente necessidade de utilização de instrumentos lúdicos para o desenvolvimento do aprendizado.

Nesse sentido, o professor de História se depara com o desafio de um currículo mínimo da disciplina que requer que sejam trabalhados conteúdos de tempos históricos e espaços geográficos muito distantes da realidade dos estudantes.

Este trabalho tem como objetivo discutir de que maneira o conhecimento histórico sobre a pré-história e a antiguidade pode ter como suporte experiências arqueológicas e a multidisciplinaridade no processo de aprendizagem.

\footnotetext{
2 O texto foi escrito em 2011. Por isso, a autora ainda utiliza como parâmetro quarta e quinta séries, atualmente esta demarcação se enquadra com quinto e sexto anos.
} 


\section{Desafios da arqueologia na sala de aula}

Já no primeiro ano do segundo segmento do Ensino Fundamental, a disciplina de História tem como objetivo a análise das relações humanas desde o período da Pré-História até o período da decadência do Império Romano. O estudo sobre a Pré-História e a Antiguidade dos povos da Mesopotâmia, Egito, Grécia e Roma é distante cronologicamente e geograficamente da realidade dos estudantes latino-americanos. Nesse sentido, o docente não pode se afastar da ideia de que

"Aprender história significa contar a história, isto é, significa narrar o passado a partir da vida no presente. O principal objetivo é elaborar uma orientação relacionada com a construção da identidade de cada um e, também, organizar a própria atuação nas lutas e ações do presente, individual e coletivamente." (SCHMIDT, 2009, p. 37)

Por isso, é um grande desafio para os professores de História o desenvolvimento do processo ensino-aprendizagem das temáticas que circundam o sexto ano. O excesso de abstração para o desenvolvimento dos estudos históricos pode ser dificultoso para estudantes que estão em processo de adaptação no decorrer do primeiro ano do segundo segmento do Ensino Fundamental.

A estruturação de textos, em especial os livros didáticos, que se preocupam em trazer o máximo possível de informações a um estudante que está em processo de amadurecimento acadêmico, também se transforma em um grande problema para o desenvolvimento do aluno. Como aponta Bittencourt,

“(...) o livro didático é também um depositário de conteúdos escolares, suporte básico e sistematizador privilegiado dos conteúdos elencados pelas propostas curriculares; é por seu intermédio que são passados os conhecimentos e técnicas considerados fundamentais de uma sociedade em determinada época." (BITTENCOURT, 1998, p. 72)

Além disso, segundo Marlene Cainelli,

"Esta utilização do livro como detentor do conhecimento não se restringe ao momento de exploração e discussão dos conteúdos. O professor também pauta no livro muitas das atividades desenvolvidas durante a aula e, quando estas não são propostas pelo livro didático, são com consulta ao material didático e às anotações do caderno. Ou seja, o livro não só transmite o que eles precisam saber para discutir com o professor, 
mas também retoma e delimita as informações que eles devem reter. Até quando o professor traz uma atividade impressa de casa, esta dialoga com os textos informativos do livro didático e com seu vocabulário.” (CAINELLI, 2011)

Nesse sentido, reconhecemos que cópias de material sistematizado em quadros, exposições meramente ilustrativas de imagens e vídeos que abordam o conteúdo a ser trabalhado pelo professor em sala de aula não são suficientes para o desenvolvimento dos alunos de sexto ano. Por isso, atividades lúdicas em que o estudante experimente outras vivências são alternativas para complementar (e não substituir) o uso do quadro pelo professor, a leitura dos livros didáticos coletivamente ou individualmente e o ato de assistir vídeos propostos por professores ou não.

Quando o professor de História inicia os estudos sobre a Pré-História e a Antiguidade, ocorrem inúmeras dificuldades para propor atividades lúdicas. Em muitos municípios brasileiros há a impossibilidade de realizar visitas técnicas a sítios arqueológicos do período Pré-Histórico. Além disso, nem todos os museus brasileiros possuem indícios da história dos povos estudados pelos alunos neste ano escolar. Também não podemos deixar de lado o fato da sociedade brasileira ter perdido grande parte do acervo do Museu Nacional em virtude de um incêndio. Isso dificulta ainda mais a possibilidade de proporcionar ao estudante o contato com cultura material produzida por esses povos.

Para tentar suprir a falta de ludicidade nas aulas sobre a pré-história, a proposta inicial foi a da criação artificial do ambiente de um sítio arqueológico. Assim, foi possível levar parte da vivência de um laboratório de arqueologia para o ambiente escolar. Ao experimentarem os estudos arqueológicos, os estudantes poderiam perceber a importância do diálogo entre o conhecimento de diversas disciplinas para a produção do conhecimento, algo inerente à arqueologia e importante para o estudante do sexto ano que deixa de ter diversas disciplinas com um único docente, passando a ter contato com professores especialistas.

Para tanto, faz-se necessário que o professor de História aponte as conexões de conteúdos entre a disciplina de História e das outras disciplinas escolares, o que se torna mais fácil com a arqueologia em sala de aula. Isso pode ocorrer se a aula abordar a leitura dos vestígios humanos em artefatos arqueológicos, o professor pode apontar questões como os desgastes químicos e físicos sofridos pelo artefato em contato com a terra e eventuais soterramentos de uma região em virtude de eventos geográficos. É possível apontar até mesmo a datação de materiais pela técnica de Carbono 14 ou pela Fotoluminescência. Esse tipo de trabalho já aponta conexões entre as disciplinas de História e Ciências. 
As reflexões presentes neste artigo partiram da minha experiência como professor de três turmas de sexto ano no desenvolvimento do projeto "Arqueólogos do Saber", no ano de 2017, na Escola Municipal Frei Gaspar, localizada no bairro de Vargem Grande, na cidade do Rio de Janeiro, tendo como público alvo estudantes matriculados regularmente na unidade escolar.

A ideia era a criação de sítios arqueológicos artificiais para que os estudantes experimentassem o ato de escavar e assim compreender o processo de investigação sobre os vestígios humanos por parte da arqueologia, como continuidade dos estudos sobre a PréHistória e a Antiguidade.

Como forma de demarcar que o conteúdo de uma aula de História pode ir além das páginas de um livro ou da moldura de um quadro branco, tingido pela caneta nas mãos do professor, foi importante que nenhuma das atividades fossem desenvolvidas fora do período das aulas regulares de cada turma. Tínhamos três tempos de cinquenta minutos por semana para cada grupo. Além disso, o período de desenvolvimento das atividades não poderia ultrapassar o período de um mês, já que não era o único professor da disciplina na escola e importantes conteúdos que não fossem abordados com os estudantes naquele ano escolar correriam o risco de serem desprezados no ano seguinte.

Para o desenvolvimento das atividades, o aluno se fez protagonista do processo do início ao fim. No início da atividade, foi solicitado para cada grupo que os estudantes se organizassem para levarem à escola itens de uma lista de materiais que incluía colheres de pedreiro, ossos de animais, pedras, barbantes, escovas de dentes, tigelas, carvão vegetal, etc.

O local utilizado para a montagem do sítio arqueológico artificial foi uma área da unidade escolar anteriormente destinada ao que seria a horta da escola, e que estava em desuso. Três canteiros foram utilizados, cada um por uma turma. Era importante que os estudantes não soubessem onde escavar para encontrar os artefatos. Por isso, uma turma não podia escavar o próprio sítio arqueológico.

$\mathrm{Na}$ primeira etapa de execução, os alunos tiveram uma aula em campo sobre a vivência do homem no período Pré-Histórico. Com o auxílio do docente, foi montado um pequeno círculo com pedras e no interior foi colocado carvão vegetal. Dentro do círculo e ao redor, foram despejados ossos de animais e foi colocado um instrumento de caça, composto por uma pedra amarrada em dois galhos. O objetivo desse momento foi discutir a importância do controle do fogo pela humanidade; a utilização e construção de ferramentas pelo ser 
humano para facilitar seus atos cotidianos; e hábitos alimentares de sociedades caçadorascoletoras.

O momento de escavação foi um grande desafio executado coletivamente pelos integrantes dos grupos. Cada área arqueológica foi separada por quadrantes e os alunos separaram o material encontrado em cada quadrante em sacos plásticos diferentes. Para melhor organizar quem escavou onde e o que cada um descobriu, foi exigido de cada estudante a produção de um caderno de campo. Além disso, o objetivo era o desenvolvimento da produção escrita do estudante com o registro de sua vivência como pequeno arqueólogo.

Após serem separados, os artefatos foram levados para serem limpos e catalogados. Os materiais foram limpos com a utilização de tigelas e escovas de dentes. A ideia foi criar a consciência do desperdício da água, pois em hipótese alguma poderia ser utilizada água corrente no processo de limpeza.

Após a limpeza, a sala de aula se transformou em um grande laboratório. O diâmetro e o tamanho dos pedaços de carvão eram catalogados justamente para os estudantes perceberem que aquele material era vestígio sobre a flora da região. $\mathrm{O}$ tamanho dos ossos que estavam colocados ao redor da fogueira também serviu para abordar a questão da fauna e os hábitos alimentares da humanidade no decorrer da Pré-História. Além disso, os instrumentos de caça produzidos pelos colegas e, posteriormente, escavados e limpos, foram uma importantes ferramentas para compreender a diferença entre os períodos Pré-Históricos do Paleolítico e Neolítico. Também foi abordada, em sala de aula, temáticas, como por exemplo: a influência humana no meio ambiente; a importância dos vestígios humanos para a História; a formação do solo; as técnicas de datação em Carbono 14; e Fotoluminescência, além das formas de produção de fogo, cerâmica, vidro e outros indícios encontrados com frequência em sítios arqueológicos.

Ao término das escavações, começou mais um desafio: a criação de um painel de pinturas rupestres. Com o objetivo de dar maior visibilidade ao estudante como protagonista do processo de ensino-aprendizagem, a direção da escola autorizou a utilização do muro da quadra, que fica voltado para a parte da frente da escola. Assim, todos os que passassem poderiam apreciar a produção dos alunos.

Em um primeiro momento, os estudantes tiveram uma aula sobre a diversidade das pinturas rupestres. O grande painel foi separado igualmente para a efetiva participação de todas as turmas. Sobre o material utilizado na produção do painel, a escola cedeu para o projeto tinta guache. Cada estudante teve a liberdade de produzir o que quisesse no local, 
desde que não houvesse nada em linguagem verbal. Representações de seres humanos e animais estiveram presentes no grande painel.

Mas, o que esteve mais presente na produção do painel foi a vontade de cada um em imprimir a sua identidade na escola ao manchar a mão com tinta e carimbar na parede. Marcas que deixaram claro o sentimento de pertencimento daqueles estudantes ao espaço escolar e as marcas que a escola deixou neles.

Ao aproximar a vivência arqueológica ao cotidiano dos estudantes de três turmas de sexto ano, foi possível, no decorrer do ano letivo, a aproximação cronológica entre os alunos e o conteúdo de Pré-História. Além disso, terem experimentado a possibilidade de um aprendizado significativo, vivenciando um pouco o cotidiano de um arqueólogo, facilitou a compreensão de como a ciência arqueológica desenvolveu técnicas para a descoberta da vida cotidiana na antiguidade, a partir dos vestígios humanos.

Mesmo compreendendo que a situação vivenciada pelos estudantes foi uma simulação, ainda assim, o projeto pedagógico Arqueólogos do Saber foi uma proposta que ultrapassou as barreiras de uma sala de aula, atingindo o propósito central de aprender-fazendo com ludicidade.

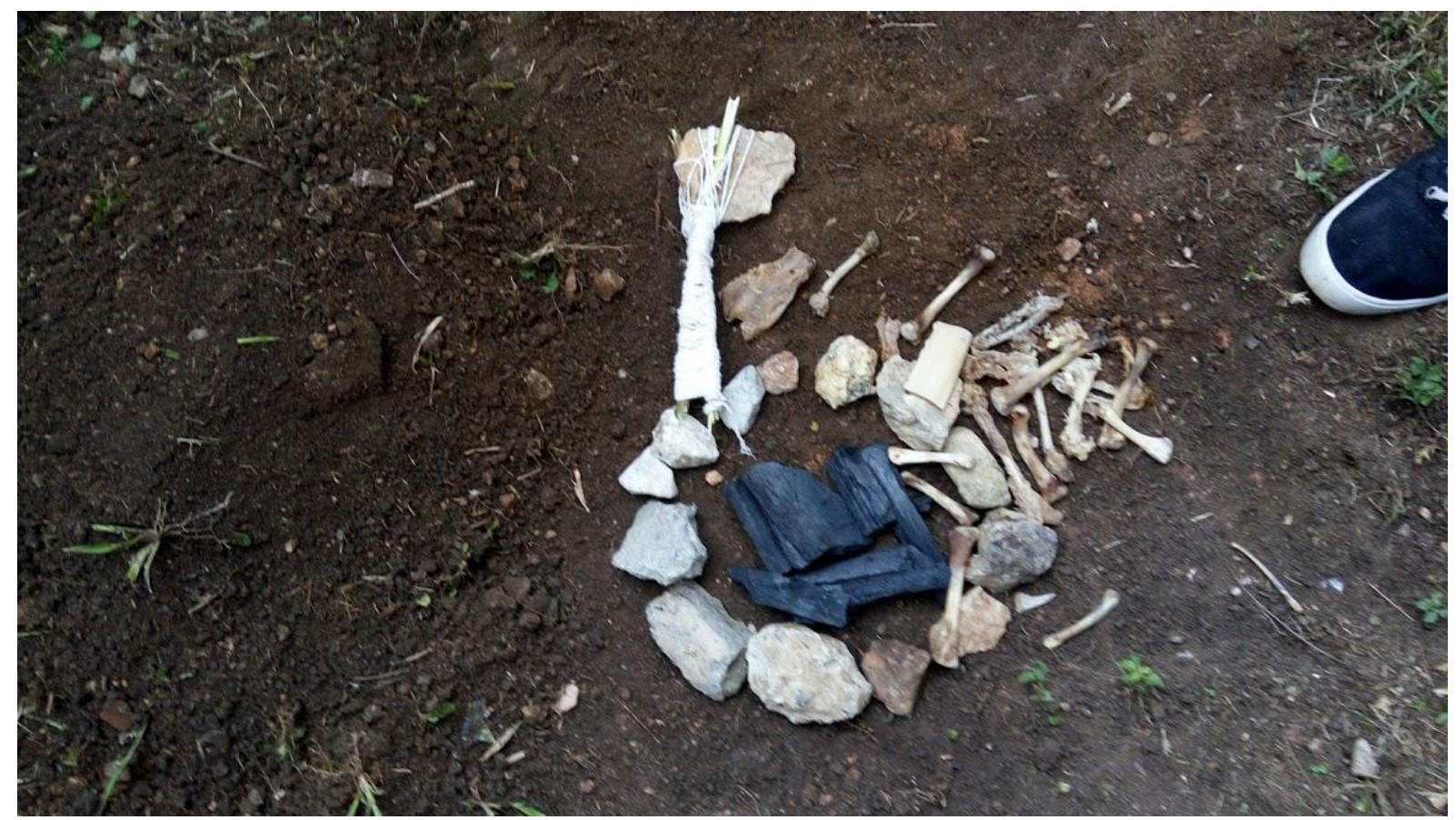

Imagem 1: Momento de montagem do Sítio Arqueológico. Fonte: Acervo Pessoal. 
RELACult - Revista Latino-Americana de Estudos em Cultura e Sociedade

Revista Latinoamericana de Estudios en Cultura y Sociedad | Latin American Journal of Studies in Culture and Society V. 05, ed. especial, mai., 2019, artigo no 1567 | claec.org/relacult | e-ISSN: 2525-7870

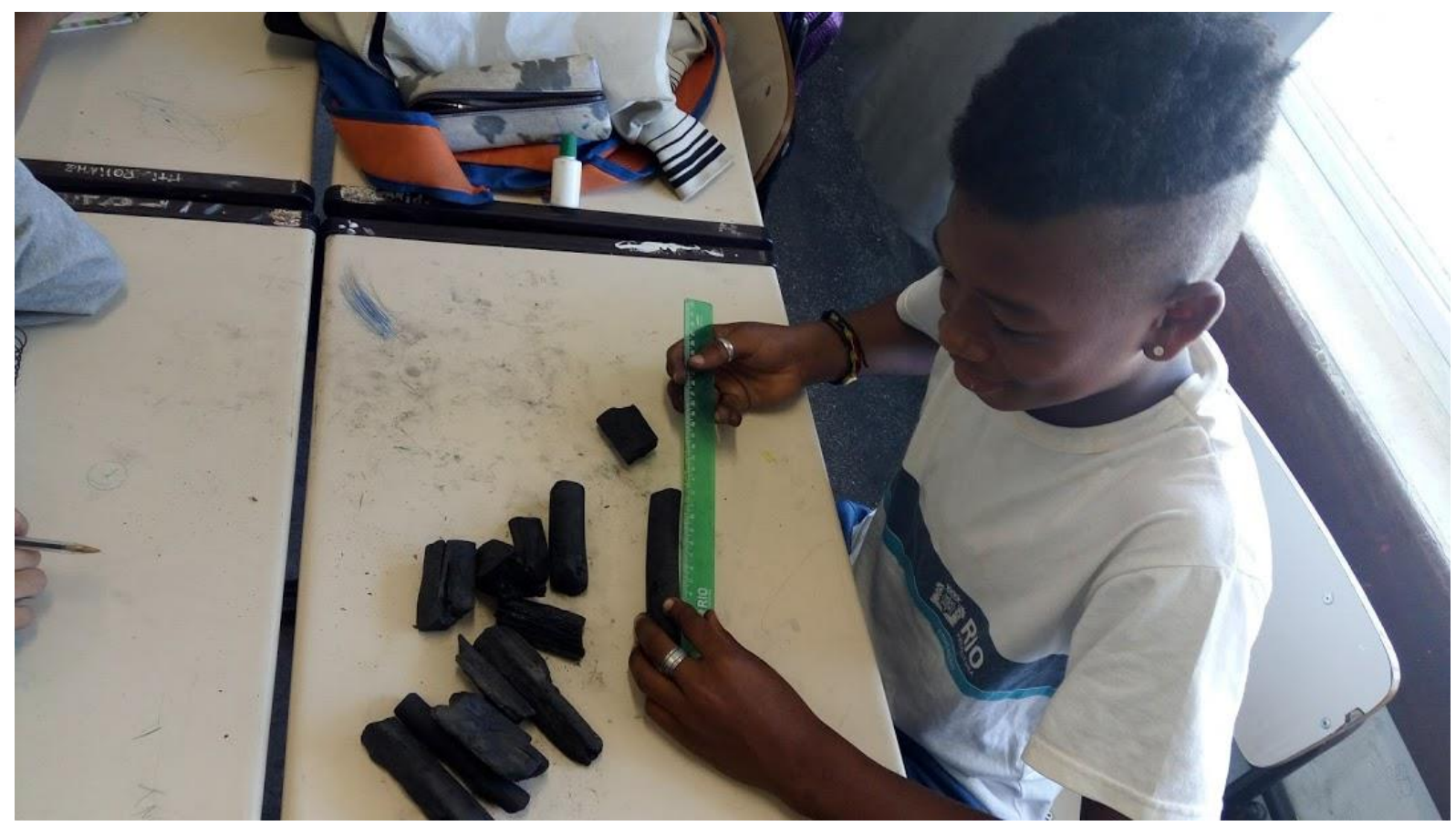

Imagem 2: Momento de análise do material recolhido no Sítio Arqueológico artificial. Fonte: Acervo Pessoal.

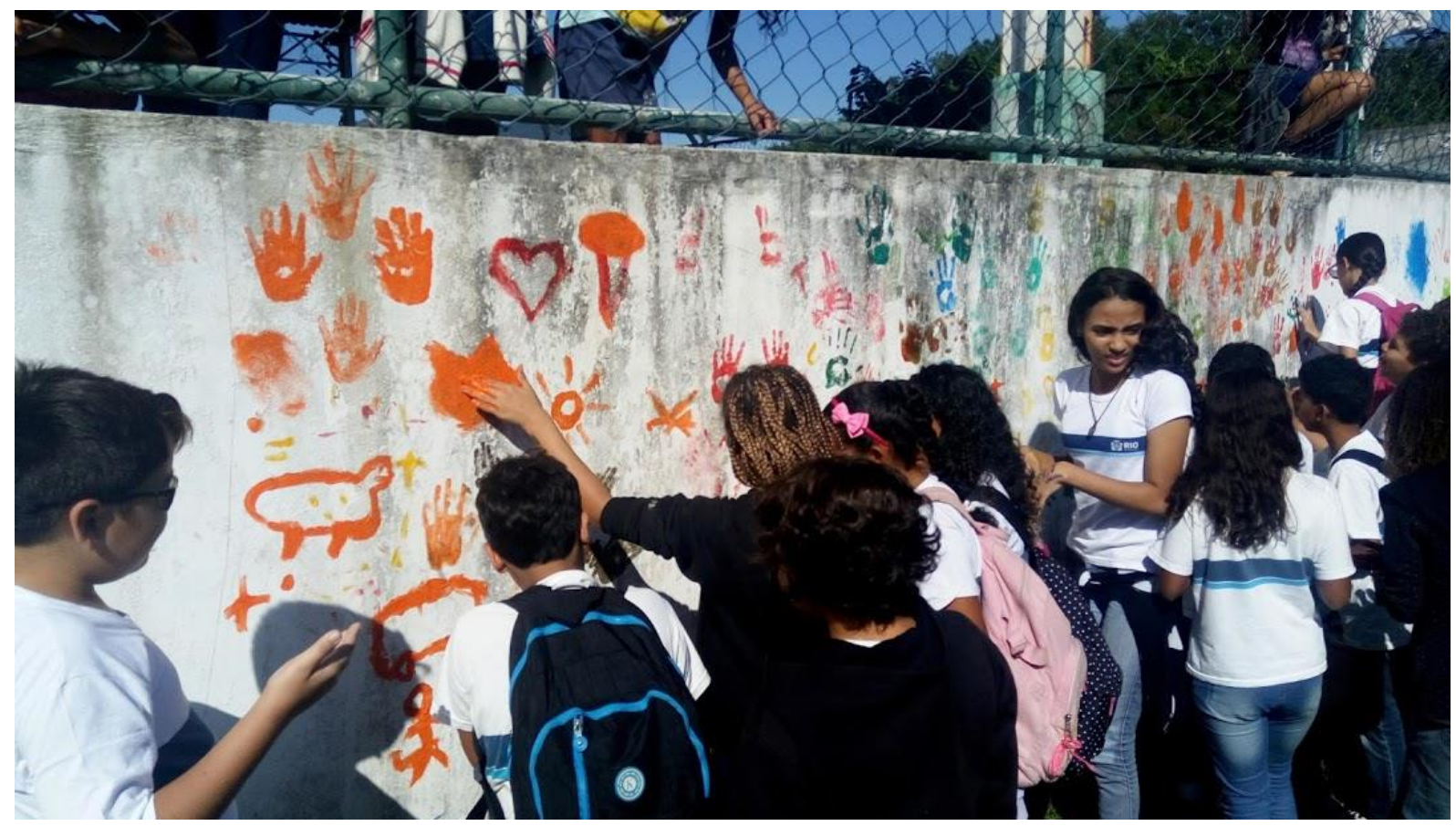

Imagem 3: Produção de pinturas inspiradas em Arte Rupestre. Fonte: Acervo Pessoal. 


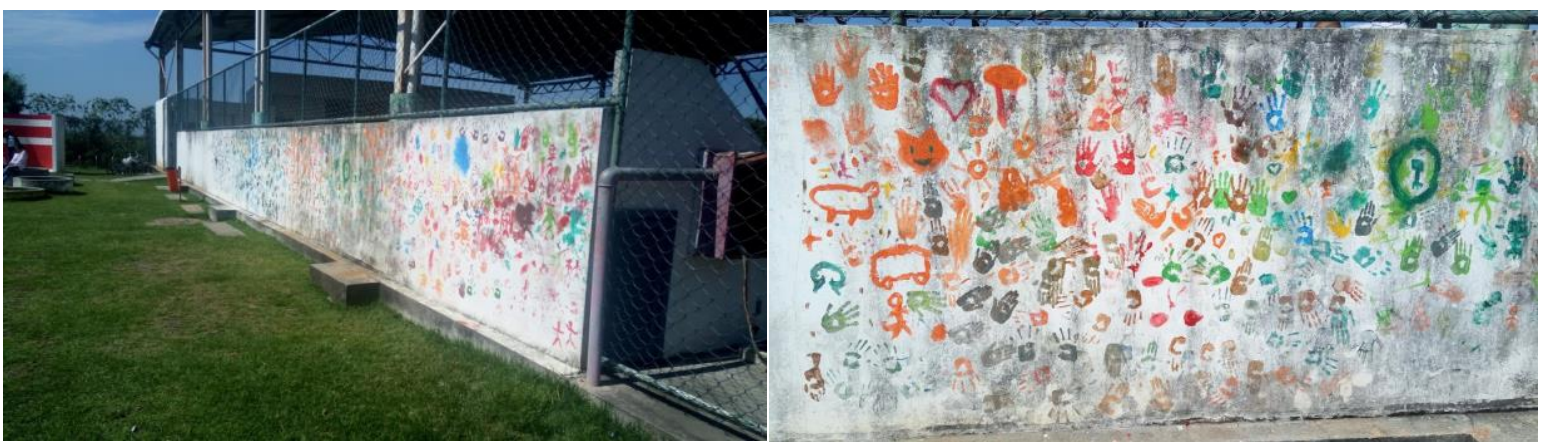

Imagem 4: Mural produzido pelos estudantes. Fonte: Acervo Pessoal.

\section{Referências}

BOAS, Franz. El arte primitivo. México: Fondo de cultura economica, 1947.

The Mind of Primitive Man.New York: Macmillan Company. 1938.

BRANCO, Renato Castelo. Pré-História Brasileira - Fatos \& Lendas. São Paulo: Quatro artes, 1971.

CAINELLI, Marlene Rosa. Entre continuidades e rupturas: uma investigação sobre o ensino e aprendizagem da História na transição do quinto para o sexto ano do Ensino Fundamental. Educ. rev. no. 42 Curitiba out./dez. 2011

CUNHA, Manuela Carneiro da. História do índio no Brasil. São Paulo: Cia. das Letras, 1992. FONSECA, Selva Guimarães. Prática e didática de ensino de História. São Paulo: Papirus, 2010

FOLEY, Robert. Principles of Human Evolution. London: Blackwells, 2003.

GADOTTI, Moacir. Concepção dialética da educação: um estudo introdutório. São Paulo: Cortez, 2001.

GOMES, Denise Maria Cavalcante. Cerâmica arqueológica da Amazônia: vasilhas da Coleção Tapajônica MAE-USP. São Paulo: FAPESP/EDUSP/ Imprensa Oficial de São Paulo. 2002.

MARTINS. Gabriela. Pré-História do Nordeste do Brasil. Recife: Abeu, 2008.

MATURANA, Humberto. Emoções e linguagens na educação e na política. Belo Horizonte: Ed. UFMG, 2002.

PROUST, André. Arqueologia Brasileira. Brasília: Editora UNB, 1992.

SCHMIDT, Maria Auxiliadora. Cognição histórica situada: que aprendizagem histórica é esta? In: BARCA, Isabel; SCHMIDT, Maria Auxiliadora (Orgs.). Aprender História: perspectivas da Educação Histórica. Ijuí: Editora Unijuí, 2009. 
SOUZA, Antôni Clarindo Barbosa de. A importância de aprender a Pré-História na Escala. In:

OLIVEIRA, Thomas Bruno. Pré-História II: Estudos para arqueologia da Paraíba. João Pessoa: JRC Editora, 2011.

WARBURG, Aby. Imagens da região dos índios Pueblo da América do Norte, in:

Concinnitas, vol.1, n.8, UERJ, 2005.El Ritual de laSerpiente. Madrid, Sexto Piso, 2008. 